\title{
Erratum to: FAOSTAT estimates of greenhouse gas emissions from biomass and peat fires
}

\author{
Simone Rossi ${ }^{1,2}$ - Francesco N. Tubiello ${ }^{1}$. \\ Paolo Prosperi $^{1}$ - Mirella Salvatore ${ }^{1}$ - Heather Jacobs ${ }^{1}$. \\ Riccardo Biancalani ${ }^{1}$ • Joanna I. House ${ }^{3}$. \\ Luigi Boschetti ${ }^{4}$
}

Published online: 11 February 2016

(C) Springer Science+Business Media Dordrecht 2016

\section{Erratum to: Climatic Change \\ DOI 10.1007/s10584-015-1584-y}

In the initial online publication of this article the name of author Joanna I. House was wrongly given as Johanna I. House. This has now been corrected.

The online version of the original article can be found at http://dx.doi.org/10.1007/s10584-015-1584-y.

Francesco N. Tubiello

francesco.tubiello@fao.org

1 Food and Agriculture Organization of the United Nations, viale delle Terme di Caracalla, 00153 Rome, Italy

2 Institute for Environment and Sustainability, The European Commission Joint Research Centre, Ispra, VA, Italy

3 School of Geographical Sciences, University of Bristol, University Road, Bristol, UK

4 Department of Forest, Rangeland and Fire Sciences, College of Natural Resources, University of Idaho, Moscow, ID, USA 